\title{
Narrativas e representações sociais: professores de ensino fundamental e fracasso escolar
}

\author{
Narratives and social representation: elementary \\ school teachers and school failure
}

Narrativas y representación social: maestros de primaria y fracaso escolar Edna Maria Querido de Oliveira Chamon (iDa Suellen Patareli Miragaia (iD) $b$

Patrícia Diana Edith B. de S. e Camargo Ortiz Monteiro

\section{Resumo}

O artigo apresenta uma proposta de utilização da pesquisa narrativa na análise das representações sociais, ilustrando esse potencial diálogo por meio de um estudo na área de educação. Busca-se apreender as representações sociais de professores sobre a defasagem idade-série e, por extensão, sobre o fracasso escolar. A proposta é utilizar a narrativa como método para analisar as representações sociais. Como essas representações circulam na comunicação e são construídas socialmente, elas podem se revelar nas narrativas dos sujeitos pesquisados. O estudo foi realizado com 14 professores de ensino fundamental, sete de Matemática e sete de Língua Portuguesa, de uma rede pública municipal do interior do Estado de São Paulo. Estes professores trabalhavam em um programa de recuperação de aprendizagem com alunos de $6^{\circ}$ a 90 ano. As narrativas foram construídas a partir de entrevistas individuais semi-

a Universidade Estácio de Sá (UNESA), Rio de Janeiro, RJ, Brasil. Doutora, e-mail: edna.chamon@gmail.com

b Universidade Estácio de Sá (UNESA), Rio de Janeiro, RJ, Brasil. Mestre em Educação, e-mail: patareli33@gmail.com

c Universidade de Taubaté (UNITAU), Taubaté, SP, Brasil. Doutora em Ciências ambientais, email: patyortizmonteiro@terra.com.br 
estruturadas cuja questão central versava sobre como eram os alunos com defasagem idade-série e como se desenrolava o programa de recuperação. A análise das entrevistas incorporou os esquemas próprios dos estudos com narrativas, buscando identificar histórias e materiais contextuais, e reconstruir o significado amplo dessas histórias na forma de grandes temáticas organizadoras das representações sociais. Os resultados obtidos apontam para uma lógica de exclusão na qual a escola é vista positivamente e isenta de responsabilidades, e o fracasso escolar - aqui representado pela defasegem idade-série e suas consequências - tem como causa uma família desestruturada e um aluno a quem falta empenho ou interesse.

Palavras-chave: Desfasagem idade-série. Programa de recuperação de aprendizagem. Representações sociais. Narrativas. Professores de ensino fundamental.

\section{Abstract}

The article presents a proposal for the use of narrative inquiry in analysis of social representations, illustrating this potential dialogue through a study in education. It seeks to apprehend the social representations of teachers about the age-grade discrepancy and school failure. As social representations circulate in communication and are socially constructed, they can reveal themselves in the narratives of the researched subjects. The study was carried out with 14 teachers of elementary education, seven of Mathematics and seven of Portuguese, from a micaunicipal public network in the State of São Paulo, Brazil. These teachers worked on a learning recovery program with students from the 6th to the 9th grade. The narratives were constructed based on individual semi-structured interviews whose central question was about how the students with an age-grade discrepancy were perceived by teachers and how the recovery program was carried out. The analysis of the interviews incorporated the schemes of study with narratives, seeking to identify stories and contextual materials, and to reconstruct the broad meaning of these stories in the form of major themes that organize social representations. The results obtained point to a logic of exclusion in which the school is viewed positively, and school failure represented here by the age-grade discrepancy and its consequences - is caused by an unstructured family and a student who lacks commitment or interest.

Keywords: Age-grade discrepancy. Learning recovering program. Social representations. Narratives. Elementary school teachers.

\section{Resumen}

El artículo presenta una propuesta para el uso de la investigación narrativa en el análisis de representaciones sociales, ilustrando este diálogo potencial a través de un estudio en educación. Busca comprender las representaciones sociales de los docentes sobre la defase edad-curso y el fracaso escolar. las representaciones sociales circulan en la comunicación y se construyen socialmente, y pueden revelarse en las narraciones de los sujetos investigados. El estudio se realizó con 14 profesores de educación primaria, siete de Matemáticas y siete de Portugués, de una red pública em una ciudad en el Estado de São Paulo, Brasil. Estos maestros trabajaron en un programa de recuperación de aprendizaje con estudiantes del $6^{\circ}$ al $9^{\circ}$ grado. Las narrativas se 
construyeron en base a entrevistas semiestructuradas individuales cuya pregunta central era sobre cómo los maestros percibían a los estudiantes con una defase edadcurso y cómo se llevaba a cabo el programa de recuperación. El análisis de las entrevistas incorporó los esquemas de estudio con narrativas, buscando identificar historias y materiales contextuales, y reconstruir el significado amplio de estas historias en forma de temas principales que organizan representaciones sociales. Los resultados obtenidos apuntan a una lógica de exclusión en la que la escuela es vista positivamente, y el fracaso escolar, representado aquí por la defase edad-curso y sus consecuencias, es causado por una familia no estructurada y un estudiante que carece de compromiso o interés.

Palabras clave: Defase edad-curso. Programa de recuperación de aprendizaje. Representaciones sociales. Narrativas. Maestros de educación primaria.

Innombrables sont les récits du monde.

Roland Barthes

\section{Introdução}

"Inumeráveis são as narrativas do mundo". A citação de Barthes (1966), na verdade, a primeira frase de seu artigo sobre a análise estrutural das narrativas, nos lembra da variedade e da antiguidade das narrativas. Presente "[...] no mito, na lenda, na fábula, no conto, na novela [...]” e em mais dez outras formas de comunicação que o autor cita, a narrativa é “[...] internacional, trans-histórica, transcultural [...]", ela existe "[...] como a vida" (p. 1).

Como vários autores apontam, a "[...] narrativa pode ser tanto um método como um fenômeno de estudo" (CRESWELL, 2007, p. 54). Assim, enquanto Barthes se preocupou com a narrativa como fenômeno e objeto de estudo, nossa proposta é utilizar a narrativa como método para apreender as representações sociais.

Embora, como veremos, as representações sociais trabalhem com material de linguagem, o diálogo com a narrativa não é trivial ou imediato, em vista da natureza subjetiva da narrativa. Por exemplo, na busca de compreensão da doença, do luto ou do abuso, é possível considerar a narrativa de apenas um indivíduo (ou dois ou três) como representativa do fenômeno que se estuda (CRESWEEL, 2007, p. 213ss). As representações sociais são fenômenos coletivos e o que se busca é o conhecimento 
de senso comum associado a um objeto de representação, que pode ser a doença ou o luto ou o abuso, mas enquanto construção coletiva. É esse diálogo que nos propomos a construir neste artigo.

O texto está organizado em quatro seções, às quais se junta esta, de caráter introdutório. $\mathrm{Na}$ primeira seção discute-se o conceito de representação social, sua multidimensionalidade e suas funções nos processos grupais. É uma seção de caráter teórico e metodológico, na qual se avança não apenas a conceituação das representações sociais, mas também sua posição chave nas ciências sociais, no cruzamento de ideias da psicologia e da sociologia. De um ponto de vista metodológico, expõe-se brevemente os caminhos disponíveis ao pesquisador para o estudo das representações sociais.

A segunda seção discute o uso de narrativas em pesquisas de representação social. A discussão enfatiza o aporte que a pesquisa narrativa traz para estudos realizados sob a ótica das representações sociais, reforçando seu papel na produção de conhecimento sobre práticas experienciadas. A aplicação das narrativas como método para as representações sociais é ilustrada com um estudo na área de educação.

A terceira seção fala de um programa desenvolvido em uma rede pública municipal de ensino cujo objetivo era a recuperação paralela de alunos com defasagem idade-série. Baseado em um conjunto de entrevistas com professores que participaram do programa, busca-se apreender as representações sociais desse grupo sobre a defasagem idade-série e, por extensão, sobre o fracasso escolar.

Apresentamos, na quarta e última seção, alguns comentários e reflexões como forma de conclusão.

\section{As representações sociais}

Na consagrada formulação de Denise Jodelet (JODELET, 1989, p. 36, tradução nossa) a representação social é “[...] uma forma de conhecimento, socialmente elaborada e partilhada, com um objetivo prático e que contribui para a construção de uma realidade comum a um conjunto social". 
Enquanto forma de conhecimento, poder-se-ia imaginar que as representações sociais estariam limitadas a seus aspectos cognitivos. No entanto, sua concepção e compartilhamento social apontam firmemente para outras dimensões - afetiva, cultural, social —, e as colocam nas origens da construção da realidade para um grupo. Como já alertava Rouquette (1994, p. 72), a representação é vista como verdade: "A maior parte do tempo, cada um está convicto de que fala sobre a realidade das coisas, quando de fato apenas exprime sua compreensão dessa realidade" (tradução nossa).

As funções que as representações sociais desempenham também apontam para essa multidimensionalidade. De fato, conforme ensina Abric (1994), as representações respondem primariamente a quatro funções essenciais:

a) Função de Saber: de carácter explicitamente cognitivo, essa primeira função é a de compreender a realidade. Função cognitiva, sem dúvida, mas mediada pelo quadro preexistente de concepções e valores do grupo.

b) Função identitária: claramente sociopsicológica, é função da representação social inserir os indivíduos e o grupo no campo social, construindo uma identidade de grupo “[...] compatível com normas e valores social e historicamente determinados" (MUGNY; CARUGATI, 1985, p. 183, tradução nossa).

c) Função de orientação: cognitiva e comportamental, a representação social funciona a priori como guia para a ação; ela antecipa a interação e aponta ${ }^{1}$ para as práticas e os comportamentos apropriados para a situação, levando em consideração as regras e as relações sociais.

d) Função de justificação: social e psicológica, a representação social permite aos atores uma explicação e justificação a posteriori das ações.

Dessa forma, a presença da representação social nas múltiplas dimensões das relações interindividuais e intergrupais faz dela tanto um fenômeno central dos

\footnotetext{
${ }^{1}$ Abric, em seu texto, fala de uma representação social prescritiva de comportamentos. Parecenos mais adequado falar em uma representação que limita o universo possível de ações ou, acompanhando Doise (1986), ver na representação social um princípio gerador de tomada de posição.
} 
processos grupais, como um conceito teórico chave para o estudo desses processos. Conceito chave, também, por romper com o dualismo sujeito-objeto, caro a uma psicologia social de cunho psicológico e que tem o indivíduo como unidade básica de análise. A teoria das representações sociais, ao adotar como modelo a análise da relação ternária indivíduo-objeto-outro, transfere a ênfase da psicologia social para o estudo das relações sociais e de como elas influenciam a construção de um objeto e são influenciadas por ele.

Sendo a representação social um conhecimento (de senso comum) partilhado no grupo, a comunicação é sua forma primária de circulação. É por meio dos processos comunicativos que as representações sociais se transmitem e também por esses processos que elas são construídas e reconstruídas no grupo. Essa (re)construção tem caráter reflexivo: práticas sociais são constantemente examinadas e redefinidas à luz de novas informações sobre estas próprias práticas e esse processo circular atualiza dinamicamente as representações sobre essas práticas. Por outro lado, as representações sociais tem um caráter de permanência, assegurando alguma estabilidade epistêmica do objeto representado. As práticas modificam-se mais rapidamente do que nossa ideia sobre elas. Processos de simplificação do objeto de representação social (objetivação) e de integração do que é estranho a uma rede de conceitos familiares (ancoragem) permitem a integração "suave" do novo.

Essa dinâmica dupla — reexame constante de novas informações e integração seletiva e controlada do que é novo — responde por uma "permanência evolutiva" das representações, permitindo ao grupo, a todo momento, situar-se e navegar na realidade.

\section{O estudo das representações sociais}

“Os estudos sobre representações sociais dizem respeito a material de linguagem (respostas a questionários, associações livres, entrevistas etc.)" (DOISE; CLEMENCE; LORENZI-CIOLDI, 1992, p. 25, tradução nossa). Sendo uma construção coletiva, que circula nas comunicações e que se mostra como "opaca a si mesma" (isto é, a representação social não se coloca em questão enquanto 
representação), as representações sociais vão ser apreendidas de forma indireta, a partir de vestígios presentes nas comunicações do grupo.

Como as representações não se apresentam a si mesmas como tal e como não é possível perguntar diretamente aos sujeitos quais são suas representações, seu estudo passa pela coleta e análise de opiniões, crenças, valores dos indivíduos de um grupo social relativamente ao objeto de representação que se deseja estudar, pois esses são elementos constitutivos das representações sociais.

Esses elementos correspondem aos conteúdos daquilo que se nomeia "Campo da representação" e que é uma de suas dimensões descritivas. Além do campo, o conteúdo de uma representação social inclui o nível de informação — quantidade e qualidade da informação disponível sobre o objeto de representação - e a atitude, orientação e posicionamento afetivo dos atores sociais em relação ao objeto.

No entanto, uma representação social é mais do que seu conteúdo. Ela supõe uma organização e uma coerência interna desse conteúdo, um campo estruturado, como denominou Jodelet (1989), que corresponde a um metassistema de regulação do pensamento, que controla verifica e seleciona conteúdos (MOSCOVICI, 2012).

Assim, o estudo das representações sociais por meio de seu conteúdo exige um duplo exercício, empírico e teórico: coletar, por meio de instrumentos e técnicas de terreno, os conteúdos de representação (valores, crenças etc.); e, trabalhar teoricamente esses conteúdos buscando um fundamento organizador para eles.

Uma possibilidade vislumbrada pelo próprio Moscovici (MOSCOVICI; VIGNAUX, 1994) é o conceito de thêmata. Na origem, esse é um conceito da filosofia das ciências definido por Gerald Holton (LIMA, 2009) para estudar a forma como opera o pensamento científico ou, mais precisamente, a imaginação científica. Já na adaptação para as representações sociais, os thêmata (forma plural de thêma) são grandes linhas temáticas, ideias-força ou ideias-raiz, consideradas como categorias primeiras que geram ou fundamentam a representação social. A dinâmica dos thêmata vem de sua organização em oposições binárias (thêma - anti-thêma), como a oposição masculino/feminino, universal/particular etc. 
Assim, uma possível estratégia teórica de busca de organização dos conteúdos representacionais é a identificação de oposições ou tensões entre elementos binários latentes nesses conteúdos.

Outra estratégia possível, não excludente, é o uso de um conjunto de dados qualitativos, em particular narrativas e histórias de vida, para construir ideias centrais ou grandes temáticas em torno das quais se organizam as representações. Essas narrativas fornecem, a um só tempo, os conteúdos representacionais e pistas sobre sua organização.

Como se verá no relato apresentado na seção 3, usamos a narrativa como forma privilegiada tanto para a obtenção de conteúdos representacionais, como para atribuição de sentidos sobre os acontecimentos vividos.

\section{Narrativas}

Em vista das formas de apreensão das representações sociais, a aproximação e o diálogo entre seu estudo e o estudo de narrativas é quase natural. Circulando na comunicação e construída socialmente, a representação social se revela no discurso ${ }^{2}$ dos sujeitos. Tratando com educadores, nos interessam particularmente as produções dos sujeitos nas quais a experiência vivida é narrada.

Embora neste artigo estejamos utilizando a narrativa como método, isto é, abordagem para obtenção e análise de dados sobre um objeto de representação social, nos posicionamos claramente a favor da narrativa como forma (ontologicamente independente) que as pessoas usam para dar significiado a suas experiências (DWYER; EMERALD, 2017).

Formalmente, não faremos distinção entre narrativa e história (story) e consideraremos, portanto, a narrativa como conjunto de eventos organizados recontados em uma sequência temporal, ainda que não cronológica ou causal.

De um ponto de vista epistemológico, entendemos que é possível extrair conhecimento a partir das narrativas e entendemos que a teoria das representações

\footnotetext{
2 Entendemos aqui, de forma relativamente livre, o discurso como produção verbal específica de um conjunto de indivíduos que formam um grupo social. Nesse sentido, estamos próximos da ideia de conjunto de enunciados provenientes de uma mesma formação discursiva, no sentido de Pêcheux (CHARAUDEAU; MAINGUENAU, 2008).
} 
sociais é uma via para isso. Acreditamos que ela permite superar a divisão que opõe as narrativas como artefatos dialógica e socialmente construídos e as narrativas como expressão individual de estados internos (SQUIRE; ANDREWS; TAMBOUKOU, 2008). A narrativa tem usualmente foco no indivíduo e em sua experiência, mas toda narrativa está imersa no contexto social. Ao invés de operar uma separação entre essas duas lógicas, a teoria das representações sociais permite englobá-las em uma construção de sentidos próprios a um grupo social.

A questão da subjetividade, que é fortemente reivindicada na pesquisa narrativa, integra-se ao contexto de pesquisas que se utilizam da teoria das representações sociais por múltiplas vias. Primeiramente, como já apontado, pela necessária imersão do sujeito em um contexto social. Mais do que isso, no entanto, pelo reconhecimento por diversas disciplinas do impacto que as análises interpretativas e a busca de significados tem para o avanço do conhecimento, em forte oposição às propostas explicativas e causais do paradigma positivista — a clássica oposição entre Verstehen e Erklären. Considere-se, por exemplo, o credo professado pelo antropólogo Clifford Geertz:

Acreditando com Max Weber que o homem é um animal preso em teias de significações que ele mesmo teceu, considero a cultura como sendo essas teias, e sua análise há de ser, portanto, não uma ciência experimental em busca de leis, mas uma ciência interpretativa em busca de significações. O que busco é a explicação, interpretando expressões sociais que são enigmáticas em sua superfície (GEERTZ, 1973, apud BUENO, 2002, p. 15).

De maneira específica, o próprio Moscovici contribui para a explicitação do subjetivo nas representações sociais quando indica que

[...] as representações sociais são sociais pelo fato de serem um fato psicológico de três maneiras: elas possuem um aspecto impessoal no sentido de pertencer a todos; elas são a representação de outros, pertencentes a outras pessoas ou a outro grupo; e elas são uma representação pessoal, percebida afetivamente como pertencente ao ego (MOSCOVICI, 2009, p. 211).

Assim, o diálogo entre representações sociais e narrativas coloca-se naturalmente: as narrativas podem constituir, de um ponto de vista metodológico, um caminho para a apreensão das representações sociais na medida em que trazem em si as significações atribuídas pelos sujeitos à experiência vivida. 
Vistas como trajetórias, as narrativas — olhadas coletivamente sob a ótica das representações sociais — constroem uma tendência interpretativa sobre um objeto de representação. Cabe buscar, nesse caso, uma estrutura comum que permita a análise, aquilo que Barthes chama de "[...] um princípio de classificação e um ponto focal de descrição" (1966, p. 2, tradução nossa).

\section{O diálogo e suas tensões}

No entanto, esse diálogo, se natural, não acontece sem tensões. Duas delas merecem destaque. A primeira, manifesta no último parágrafo, é a tensão entre a subjetividade (capturada na narrativa) e a forma coletiva que a representação assume no grupo. Aqui é preciso atentar para o fato de que as representações sociais não são a média ou a parte comum das opiniões, crenças, valores e atitudes dos indivíduos. De fato, como explica Doise (1986), as representações sociais são “[...] princípios geradores de tomada de posição ligadas a inserções específicas em um conjunto de relações sociais e que organizam os processos simbólicos que interveem nessas relações”. Assim, um sistema de regulação (as representações sociais) atualiza as cognições individuais (as diferentes tomadas de posição) em contexto (inserções específicas), o que permite as variações interindividuais.

A segunda tensão, de caráter mais filosófico, é aquela entre rigidez e flexibilidade. Relaciona-se com a crítica sobre o papel da teoria na pesquisa narrativa. Ocorre que, para muitos autores, a definição de um quadro teórico está associada com uma ideia de autoridade a priori, com um modelo fixo, o que levaria a uma perda de flexibilidade da análise narrativa (KIM, 2016).

Portanto, o diálogo entre a teoria das representações sociais e a pesquisa narrativa - ainda que frutífero — se equilibra entre essas tensões. Corre-se, de um lado, o risco de instrumentalizar a narrativa como pura técnica de coleta de dados e, de outro, o risco de ignorar o potencial analítico da teoria das representações sociais na análise das narrativas. 


\section{$A$ virada narrativa}

Da mesma forma que as representações sociais emergiram nos anos 1960 para caírem no esquecimento por quase dez anos e, então, reaparecem (JODELET, 1992), também a narrativa teve que aguardar um certo esgotamento do paradigma positivista para se firmar como forma academicamente respeitável de pesquisa.

Ainda que a questão das origens seja sempre enganosa, pode-se colocar os inícios da narrativa nas pesquisas sociais nos anos de 1920, com a Escola de Chicago e o trabalho de Thomas e Znaniecki "The Polish Peasant in Europe and America" (GOODSON; GILL, 2011). Após uma trajetória bem sucedida, o uso de narrativas como forma de pesquisa social caiu também no esquecimento, ressurgindo apenas nos anos de 1970 em estudos similares aos da Escola de Chicago, e nos anos de 1980, a partir dos estudos feministas que privilegiaram a abordagem de narrativas (idem). As narrativas abriram novas frentes e possibilidades de exploração da experiência humana, do poder e da dinâmica social.

A adoção da narrativa como método nos interessa pelo potencial que ela aporta para ultrapassar as limitações impostas pela necessidade positivista de observações testáveis e reprodutíveis, princípios gerais e generalizantes, e conhecimento padronizado.

\section{Os professores frente ao fracasso escolar - Relato de experiência}

A proposta aqui é ilustrar os aportes das narrativas para o estudo de representações sociais a partir de um relato de experiência de um programa de recuperação paralela de estudantes do ensino fundamental, anos finais, em defasagem idade-série de uma rede pública municipal de ensino no interior do Estado de São Paulo.

O sistema de ensino em questão possui aproximadamente 4000 alunos em defasagem idade-série entre o $6^{\circ}$ e o $9^{\circ}$ ano escolar, o que representa cerca de $13 \%$ do total de alunos das escolas nessa situação. A proposta do programa envolvia a 
recuperação de níveis de aprendizagem seguida da possibilidade de reclassificação do aluno em anos subsequentes (MIRAGAIA, 2019).

A recuperação era centrada nas disciplinas de Matemática e Língua Portuguesa e o trabalho era realizado no contraturno do ensino regular, duas a três vezes por semana, em aulas com duração de duas horas, em turmas de 10 a 15 alunos.

A análise desse programa limita-se, neste artigo, à perspectiva das narrativas de professores e de suas representações sociais sobre o programa de recuperação e sobre questões mais amplas de fracasso escolar.

\section{Procedimentos éticos}

A pesquisa foi submetida ao Comitê de Ética em Pesquisa (CEP) e foi aprovada sob o CAAE: 80305217.9.0000.5501.

Os participantes foram contactados e informados sobre o estudo e seus objetivos e assinaram um Termo de Consentimento Livre e Esclarecido, sendo-lhes garantido o sigilo de sua identidade, bem como assegurada sua saída do estudo, se assim o desejassem, a qualquer tempo.

Método

A pesquisa foi realizada em um município do interior do Estado de São Paulo, que possui 60 escolas de Ensino Fundamental e atende 30.924 alunos (dados da Secretaria Municipal de Educação relativos a 2017). Destes alunos, 3.961 estavam em defasagem idade-série, ou seja, $12,8 \%$ dos alunos da rede municipal de ensino.

O programa de recuperação foi implantado em 14 escolas, que foram, portanto, selecionadas para a pesquisa. Um total de 821 alunos dessas escolas encontravam-se em defasagem idade-série e estavam inscritos no programa.

Foram entrevistados todos os 14 professores que ministravam aulas de recuperação nessas escolas, sendo sete de Matemática e sete de Língua Portuguesa.

Uma entrevista individual semi-estruturada, na qual o entrevistado tem a oportunidade de discursar sobre suas vivências a partir de um tema central 
proposto, foi a técnica empregada para obter as narrativas dos participantes sobre a experiência que tiveram com o programa de recuperação. As entrevistas foram gravadas e depois transcritas para análise.

O roteiro da entrevista teve um tema central proposto na forma de questão que versava sobre como eram os alunos com defasagem idade-série e como se desenrolava o programa de recuperação. Os diferentes relances previstos no roteiro avançavam sobre a participação dos alunos, a relação família-escola, a formação docente para o programa.

Para a análise das entrevistas, buscou-se adaptar o esquema sugerido por Creswell (2007, p. 156-157, tradução nossa) e reproduzido a seguir:

- Criar e organizar os arquivos com os dados;

- Ler o texto, anotar nas margens, criar códigos iniciais;

- Descrever a história ou o conjunto objetivo de experiências e colocá-los em uma cronologia;

- Identificar histórias, localizar epifanias, identificar materiais contextuais;

- Interpretar o significado amplo da história;

- Apresentar a narração focalizando nos processos, teorias, características únicas e gerais da vida.

Essa adaptação se dá nas etapas finais da análise, nas quais a interpretação do "significado amplo da história" deve ser dirigida, como já indicamos, para a busca das ideias centrais ou grandes temáticas em torno das quais se organizam as representações sociais. Assim, as trajetórias apontadas nas entrevistas devem ser lidas como temas organizadores de representações, seja na forma de tensões e oposições, seja na forma de um campo estruturado construído por objetivação/ancoragem do objeto de representação, seja ainda na forma de uma estrutura central organizadora de toda a representação (como preconizado na Teoria do Núcleo Central) (SÁ, 1996).

\section{Resultados}

A maioria dos 14 docentes atuantes no programa de recuperação possui mais de 30 anos e apenas quatro possuem mais de 10 anos de experiência docente. Em relação a questão do gênero, 12 docentes são mulheres. Como já indicado, sete docentes são licenciados em Matemática e sete em Língua Portuguesa. Os professores entrevistados cumprem uma carga horária de $48 \mathrm{~h} /$ aulas, das quais 4 horas/aula são cumpridas em Horário Pedagógico Coletivo (HTPC), 4 horas/aula 
são cumpridas em Horário de Trabalho Pedagógico Livre (HTPL) e as demais (40 horas/aula), com os alunos em sala de aula, incluindo as atividades no programa de recuperação.

Quando as narrativas são analisadas, percebe-se uma convergência de falas sobre dois grandes temas, que não são opostos entre si, mas que definem uma linha lógica de pensamento sobre o programa, a defasagem e os alunos.

De forma sintética, a primeira ideia aponta para uma visão muito positiva do programa, de sua proposta e de sua organização. Os professores consideram que o programa de recuperação promove uma convivência social, que respeita o ritmo do aluno, proporcionando um modo diferente de aprender, sendo, portanto, inovador e, por consequência, um investimento na educação na medida em que procura sanar as dificuldades dos alunos, integrando-os e desenvolvendo a autoestima por meio de estratégias diferenciadas, do lúdico, com apoio de tecnologias mediadas pelos professores. Esses aspectos compõem parte das narrativas e são ilustrados em alguns trechos das entrevistas realizadas:

Bom, o programa hoje está aí para gente sanar tanto a defasagem de conteúdo como a defasagem idade-série mesmo, porque a gente vai trabalhar com o aluno toda essa dificuldade dele e assim ajudar para que ele fique na série que ele deveria estar mesmo (Professor 1).

O programa, eu vejo como um projeto maravilhoso que vem resgatar os jovens que por algum motivo ficaram com essa defasagem de conteúdo e de idade e a gente tem uma possibilidade de oferecer uma segunda chance (Professora 6).

O programa, eu vejo como um investimento na educação, uma intervenção pedagógica (Professor 2).

As formações semanais são importantes principalmente pra gente poder conversar, nós vamos trocar experiência, vamos trocar esse material, então quem sabe eu posso ajudar o meu aluno, porque a gente sabe que os alunos são diferentes, porque somos pessoas diferentes, às vezes a metodologia usada por um professor pode ajudar um outro. (Professora 2).

A última fala, relativa aos encontros semanais de formação, reforça a narrativa de um programa bem estruturado e de professores que se preparam para um ensino diferenciado. Percebe-se aqui a atitude (uma das dimensões da representação social) positiva dos sujeitos em relação ao objeto relatado.

A segunda ideia aponta para as causas da defasagem idade-série e, por extensão, para o fracasso escolar. Os professores atribuem o problema da falta de 
aprendizado em geral à desestruturação familiar e à falta de empenho ou interesse do aluno. Notáveis, pela ausência, são fatores como a infraestrutura disponível, o ambiente escolar, as estratégias de ensino, os modelos de avaliação. As narrativas concentram-se em problemas familiares, baixa autoestima, indisciplina ou bloqueio do aluno, como se verifica nos trechos a seguir:

Eles vão ficando com cada vez mais defasagem e mais desânimo, porque ele não aprendeu, ele passa para o próximo conteúdo e não consegue aprender também, aí ele vai ficando desanimado (Professora 5).

Porque esses alunos que tem defasagem de idade-série tem uma autoestima muito baixa, então eles desacreditam de tudo acham que são burros que não tem capacidade pra nada (Professor 2).

Às vezes por aspectos familiares, bloqueios na própria escola, às vezes bloqueio do próprio aluno, às vezes dificuldade do próprio aluno de aprender então tem vários aspectos que influenciam o aluno a ter essa defasagem (Professora 1).

Geralmente são alunos carentes afetivamente com familias desestruturadas, eles apresentam quadros de indisciplina, tem baixa autoestima, geralmente são assim (Professora 3).

A grande maioria são familias que não são bem estruturadas, que tem problema na estrutura familiar, os pais não participam da vida acadêmica dos alunos, são pais que muitas vezes estão separados, familias muito numerosas, problemas sociais $e$ problemas econômicos (Professora 1).

A maioria são pais que também tiveram problemas, eu acredito que tiveram esse problema de aprendizagem na escola, não estudaram também, tem uma série de problemas que dificultam a vida desses pais (Professora 3).

A última fala, relacionada à questão da família, amplia a ideia de problemas familiares para a questão da trajetória familiar de fracasso, acrescentando, às causas já apontadas, a inevitabilidade do fracasso.

Observa-se nesses registros, uma simplificação do objeto de representação social (correspondente ao fenômeno da objetivação), no sentido de se excluir das narrativas aspectos relacionados à possível responsabilidade da escola — de sua organização, de seu currículo, de sua infraestrutura. Também, observa-se a ancoragem das representações sociais em categorias (de senso comum) amplamente difundidas na sociedade, que correspondem a culpabilizar o indivíduo (aluno) pela sua condição. Esse duplo movimento de objetivação e ancoragem constrói a representação social do fracasso escolar, que se cristaliza na sociedade e transita do senso comum para a própria atividade do professor. 


\section{Considerações finais}

Retomando a proposta inicial, nossa problemática está centrada nas possibilidades de diálogo entre a pesquisa feita com narrativas e a teoria das representações sociais. Tal diálogo não é imediato, tendo em vista as possíveis tensões entre a busca de subjetividade intrínseca das pesquisas narrativas face à busca de uma construção coletiva que é típica das representações sociais.

Ainda assim, entendemos que a narrativa, enquanto método, tem muito a oferecer ao estudo das representações sociais. Primeiramente, e de forma mais instrumental, como meio de obter o material de linguagem a partir do qual se pode trabalhar e apreender as representações sociais. Depois, e talvez mais importante, pelo potencial do estudo das narrativas de reconstruir significados da experiência. Mesmo se entendendo a experiência como única, um conjunto organizado de experiências pode apontar para as grandes temáticas ou oposições em torno das quais se organizam as representações sociais.

Para ilustrar essa possibilidade de interação entre esses dois conceitosfenômeno, a narrativa e a representação social, e como aplicação ao campo educacional, propusemos a descrição de um estudo feito sobre o tema do fracasso escolar, mais precisamente sobre a defasagem idade-série. $O$ estudo buscava apreender as representações sociais de professores do ensino fundamental sobre a questão da defasagem idade-série e baseava-se em entrevistas semi-estruturadas que tinham por objetivo recuperar as crenças, opiniões, atitudes dos professores sobre um programa de recuperação de aprendizagem orientado para alunos nessa condição de defasagem. Visto pelo lado da pesquisa narrativa, o estudo buscava reconstruir, a partir das entrevistas, os significados atribuídos pelos professores à defasagem e, de forma mais ampla, à ideia de fracasso escolar no quadro daquele programa do qual participaram.

Participaram da pesquisa sete professores de Matemática e sete professores de Língua Portuguesa de uma rede pública municipal, do interior do Estado de São Paulo, engajados no programa de recuperação de aprendizagem, que trabalhavam em 14 estabelecimentos de ensino e que atenderam 821 alunos com defasagem idade-série. 
Os relatos obtidos junto aos docentes mostram que eles consideram o programa benéfico para a superação da defasagem de aprendizagem dos alunos e que as formações realizadas em serviço para os professores contribuem para o aperfeiçoamento de sua prática docente. Ao mesmo tempo, relatam que as famílias desses alunos são desestruturadas, apresentam problemas de conduta e não participam da vida escolar de seus filhos. Muitos relatam que os alunos possuem defasagem idade-série por causa dessa estrutura familiar e da falta de empenho do próprio aluno. Trata-se do estigma do fracasso que se atribui ao aluno e/ou sua família, já claramente identificado na literatura (PATTO, 1999).

Esses resultados apontam para uma lógica de exclusão na qual a escola é vista positivamente e isenta de responsabilidades, e o fracasso escolar — aqui representado pela defasegem idade-série e suas consequências - tem como causa a família (que é desestruturada) e o aluno (a quem falta empenho ou interesse). As narrativas ignoram quase por completo questões outras como ambiente escolar ou formas de avaliação.

\section{Referências}

ABRIC, J.-C. Pratiques sociales et représentations. Paris: Presses Universitaires de France, 1994.

BARTHES, R. Introduction à l'analyse structurale des récits. Communications, n. 8, p. 1-27, 1966.

BUENO, B. O. O método autobiográfico e os estudos com histórias de vida de professores: a questão da subjetividade. Educaşão e Pesquisa, São Paulo, v. 28, n. 1, p. 11-30, jan./jun. 2002.

CHARAUDEAU, P.; MAINGUENAU, D. Dicionário de análise do discurso. 2. ed. São Paulo: Contexto, 2008.

CRESWELL, J. W. Qualitative inquiry and research design: Choosing among five approaches. 2. ed. Thousand Oaks: Sage, 2007.

DOISE, W. Les représentations sociales : définition d'un concept. In: DOISE, W.; PALMONARI, A. (ed.). L'étude des représentations sociales. Neuchâtel: Delachaux \& Niestlé, 1986. p. 34-80.

DOISE, W.; CLEMENCE, A.; LORENZI-CIOLDI, Fabio. Représentations sociales et analyse de données. Grenoble: Presses Universitaires de Grenoble, 1992. 
DWYER, R.; EMERALD, E. Narrative Research in Practice: Navigating the Terrain. In: DWYER, R.; DAVIS, I.; EMERALD, E. (eds.). Narrative Research in Practice: Stories from the Field. Singapura: Springer, 2017. p. 1-25.

GOODSON, I. F.; GILL, S. R. The narrative turn in social research. Counterpoints, v. 386, p. 17-33, 2011.

JODELET, D. Représentations sociales: un domaine en expansion. In: JODELET, D. Les représentations sociales. Paris: PUF, 1989. p. 31-61.

JODELET, D. Représentation sociale : phénomènes, concept et théorie. In: MOSCOVICI, S. (ed.). La psychologie sociale. 4. ed. Paris: Presses Universitaires de France, 1992. p. 357-389.

KIM, J.-H. Undestanding Narrative Inquiry. The Crafting and Analysis of Stories as Research. Thoousand Oaks: Sage, 2016.

LIMA, L. C. L'articulation "thêmata-fond topique": fondements théoriques et application pragmatique. Langage et Société, v. 3, n. 129, p. 83-100, set. 2009.

MIRAGAIA, S. P. As representações sociais de diretores, professores e alunos sobre a defasagem idadesérie: fracasso escolar? 2019. 158 fls. Dissertação (Mestrado em Educação) — Universidade de Taubaté, Taubaé, SP, 2019.

MOSCOVIC, S. A psicanálise, sua imagem e seu público. Petrópolis: Vozes, 2012.

MOSCOVIC, S. Representações sociais: investigações em psicologia social. 6. ed. Petrópolis, RJ: Vozes, 2009.

MOSCOVICI, S.; VIGNAUX, G. Le concept de themata. In: GUIMELLI, C. (dir.). Structures et transformations des représentations sociales. Neuchâtel: Delachaux \& Niestlé, 1994. p. 25-72.

MUGNY, G.; CARUGATI, F. L'intelligence au pluriel. Cousset: DelVal, 1985.

PATTO, M. H. de S. S. A Produção do Fracasso Escolar: histórias de submissão e rebeldia. São Paulo: Casa do Psicólogo, 1999.

ROUQUETTE, M.-L. Sur la connaissance des masses. Grenoble: Presses Universitaires de Grenoble, 1994.

SÁ, C. P. Núcleo Central das Representacoes Sociais. Petrópolis: Vozes, 1996.

SQUIRE, C.; ANDREWS, M.; TAMBOUKOU, M. Introduction: What is narrative research? In: ANDREWS, M.; SQUIRE, C.; TAMBOUKOU, M. Doing Narrative Research. London: Sage, 2008. p. 1-21.

RECEBIDO: $31 / 05 / 2020$

APROVADO: $28 / 07 / 2020$

RECEIVED: 05/31/2020

APPROVED: 07/28/2020

RECIBIDO: $31 / 05 / 2020$

APROBADO: 28/07/2020 